\title{
A educação informal e a educação formal: interfaces e significados de saberes no ensino de Química em Moçambique
}

\author{
Formal and informal education: \\ interfaces and the meaning of knowledge \\ in the teaching of Chemistry in \\ Moçambique
}

\author{
Zulmira Luís FRANCISCO*
}

Resumo: No presente artigo objetiva-se reflectir sobre as relações e a relevância de duas vertentes educativas em Moçambique. Por razões históricas, culturais e sociais a educação informal ou tradicional, com as suas regras e normas, constitui um poderoso instrumento de transmissão da cultura na sociedade moçambicana. A questão fundamental discutida neste artigo é como levar para a escola, para o ensino de Química, esses saberes teóricos, práticos, de técnicas e de tecnologias.

Palavras-chave: educação formal e informal, saberes culturais, ensino de Química, Moçambique

Abstract: The aim of this article is to reflect on the connections and relevance of two educational sides in Moçambique. For historical, cultural and social reasons, informal or traditional education with its rules and norms, is a powerful tool in transmitting culture in moçambique society. The fundamental question, discussed in this article is how to take to school, more specifially in teaching Chemistry, the practical and theoretical knowledge of techniques and technologies.

Key words: formal and informal education, cultural knowledge, teaching of Chemistry, Moçambique

\footnotetext{
* Professora Auxiliar das disciplinas de Didáctica de Química e Práticas Pedagógicas na Faculdade de Ciências Naturais e Matemática da Universidade Pedagógica, Maputo, Moçambique. Email: zfrancis2002@yahoo.com.br
}

Olhar de professor, Ponta Grossa, 8(1): 141-150, 2005. 


\section{APRESENTAÇÃO}

A intenção deste texto é demonstrar que os princípios, os métodos, os conteúdos da educação informal, como parte de uma de uma cultura mais ampla de saberes e práticas quotidianas que são relevantes do ponto de vista social, ético, cultural e pedagógico. As instituições escolares e a escola, estruralmente integradas, são um lugar privilegiado para uma educação formal, de formação específica, na qual se desenvolvem a autonomia de pensamento, de acções, de habilidades e capacidades.

As relações entre os saberes quotidianos e os conhecimentos científicos na Educação têm constituído temas de debate e pesquisa, pelo papel que a escola desempenha na constituição dos saberes quotidianos, considerando-os como um pólo dinâmico no processo de ensino e aprendizagem.

A ausência de contextualização sócio-cultural na escola moçambicana revela as preocupações da parte dos investigadores nas áreas do Currículo e da Didáctica, no que diz respeito à necessidade de se buscar a compreensão e a tomada de consciência pelo respeito e valorização que os conhecimentos quotidianos merecem e de saber como eles circulam nos diversos contextos sociais. Entendendo que esse distanciamento se constitui numa das formas de exclusão escolar das camadas mais desfavorecidas, as mais recentes pesquisas educacio- nais vêm tentando demarcar-se, ainda que tímidamente, do carácter tecnicista e formal de outras pesquisas, procurando formas alternativas de situar a educação e o ensino de Química em particular, numa abordagem sócio-cultural.

\section{INTRODUÇÃO}

De um modo geral, a noção tradicional de educação é aquela que é exercida por gerações adultas sobre gerações mais jovens e tem como marco de referência as práticas sócioculturais utilizadas e que servem como meios de transmissão de valores, de normas, regras de comportamento em todas as sociedades humanas. Segundo Luzuriaga (apud OLIVEIRA, 1998), ela é vista como influência intencional e sistemática sobre o ser juvenil, com o propósito de formá-lo e desenvolvê-lo (p.225).

$\mathrm{Na}$ prática do senso comum da educação formal ou popular, educar e ensinar são considerados muitas vezes sinónimos: por exemplo, educase/ensina-se, normalmente por tradição oral, uma criança a observar e seguir um determinado comportamento diante de pessoas adultas; educa-se/ ensina-se os jovens para o gosto e apreciação das manifestações artísticas, para a prática e gosto pelo jogo que contribuem para uma iniciação dos jovens a hábitos de convivência e socialização. Nesse tipo de educação a relação entre ensinar ou educar e aprender ocorre de forma natural: as crian- 
ças aprendem como se vive na sociedade ideal por socialização, pela prática diária dos hábitos e dos costumes, por imitação aos adultos. Através de actividades lúdicas elas vão sendo iniciadas num processo de inclusão e integração social (BONNET, 2002).

Nesse sentido, a educação informal é concebida como um processso de sentido único: transmissão (pelo educador) e recepção passiva (pelo educando); tradicionalmente, o conjunto de normas, regras, valores, maneiras de ser e estar na sociedade são transmitidos de geração em geração sem que se verificarem alterações ou mudanças. Dessa perspectiva de formação humana resultam os modos de transmissão e de socialização dos saberes, das experiências sócio-culturais de valores que circulam nas comunidades, as quais se propõem como principais referências para o âmbito da educação escolar. As formas distintas pelas quais os saberes populares são construídos e produzidos são responsáveis pela reprodução física, social, cultural das populações. SACRISTÁN (2002, p.220-222) considera a familia e as pequenas comunidades, os ambientes primários cuja função é proporcionar a identidade básica aos alunos, de acordo com a adaptação ao meio imediato, pela experiência directa, significativa, e integrada no sentido em que engloba aspectos sociais, afectivos, morais, cognitivos e corporais.

No âmbito mais restrito a educação realiza-se com finalidades especí- ficas, de instrução e de ensino por acções conscientes mediante objectivos e metodologias definidos conscientemente. Até há pouco tempo essa educação era vista como um dos meios de conservação e de perpetuação da história e da cultura humana pela transmissão de determinados conteúdos através das gerações, sem consideração às particularidades históricas, sociais e culturais e ignorando-se as reais expectativas dos alunos. Quando lidamos com os nossos alunos esquecemos que eles chegam à escola com as suas próprias concepções da ciência e pretendemos que eles aprendam pela "primeira vez". Ainda que esses saberes estejam ainda num nível elementar, é preciso reconhecer que essas concepções foram assimiladas durante a educação fora do espaço físico escolar, em grupos sociais diferentes, com práticas e maneiras de tratar que é preciso levar em consideração nas disposições curriculares.

Apesar das diferenças decorrentes dos propósitos e das finalidades dos dois tipos de educação, conservando ou renovando as suas culturas, em sentido mais amplo, ambas almejam a coesão dos membros de uma sociedade, ao aproximar sujeitos com experiências culturais diversas e aproveitar de cada experiência as suas potencialidades forma-tivas. Com base nisso, pode-se afirmar que a educação é uma prática universal nos dois sentidos: de que ocorre universalmente em todos os povos; e de que 
implica a universalidade dos saberes (CASALI, 2003, p.3). Essa é uma razão pela qual a escola não deveria minimizar e mesmo ignorar que o ambiente extra-escolar e os saberes (na sua acepção ampla, de saberes cognitivos, de técnicas, de práticas e os procedimentos) sócio-culturais são também importantes na direcção e avanço da ciência.

\section{REFLEXÕESSOBREAEXCLUSÃO ESCOLAR E CONTRIBUIÇÕES DOS SABERES QUOTIDIANOS PARAO ENSINO DE QUIIMICA}

Neste texto, considera-se fundamental o desafio que a busca de interfaces no conhecimento ensinado e o mundo dos conhecimentos e práticas forjadas no quotidiano social e cultural dos alunos representam para o ensino de Química em particular. A tese geral da incorporação dos estudos sócio-antropológicos na educação vem reforçar essa temática e propor novas metodologias de ensino e aprendizagem, baseada no facto de que esse processo precisa relacionar-se com as condições sócioculturais externas ao sistema escolar.

Tratando-se de uma abordagem relativamente recente das actuais pesquisas educacionais, parece-me correcto enfatizar a necessidade de o ensino formal criar oportunidades para uma abordagem no emergente campo das etnociências e das respectivas etnometodologias, como um imperativo ético e cultural na produção de conhecimentos. O desafio dos estudos nesse campo é estabelecer os seus fundamentos, as suas características e as respectivas implicações para os fins educativos. Isso porque, segundo D’Olne Campos (s.d., p. 11), são reconhecidas as dificuldades que se apresentam no estudo de formas diversas de saberes, de práticas, de técnicas e de procedimentos que estão presentes entre a diversidade sócio-cultural mundial, o que significa que a compreensão das suas relações com a escola implica muita aprendizagem e pesquisa a respeito.

Por outro lado, a hegemonia científica institucionalizada, ao insistir que ela própria basta-se para explicar-se por si mesma, rejeita as contribuições da actividade quotidiana dos actores sociais visando enfraquecer a diversidade e diversificação das culturas populares. Assim, essas contribuições são mantidas no terreno da doxa (opinião) ou do mito (LOPES, 1993). Sendo uma das carcterísticas essenciais da cultura, a diversidade deve ser considerada um factor importante de oposição à cultura dominante, que se manifesta predominantemente cientificista e tendente ao universalismo formal. Casali (2001) menciona que só o diverso produz novas qualidades.

O que se verifica nas actuais práticas de ensino, de um modo geral, é um distanciamento e desprezo entre o que os alunos trazem do seu quotidiano sócio-cultural e aquilo que encontram na escola como matéria es- 
pecífica de formação instrucional. Nesse sentido, estão em causa valores e práticas que são a referência cultural dos alunos. Certamente que não se ignora que o desenvolvimento social e económico dos países depende em grande medida do conhecimento e domínio de técnicas e tecnologias melhor elaboradas cuja sofisticação implica, por seu lado, exigências curriculares adequadas às regras do mundo moderno em que vivemos.

Há, no entanto, que se destacar que o mundo global do qual fazemos parte deve ser uma realidade que tenha significado para cada um de nós e que represente o resultado de integração de uma rede de relações sócio-culturais que nos vinculam a outras comunidades de conhecimento e de culturas mais amplas.

Moçambique é um país com uma história e experiência de independência política, económica e de soberania relativamete recente. Divergências de âmbito político e ideológico, que resultaram em conflitos armados nos anos do pós-independência (junho de 1975), contribuiram para o estado de fragilidade económica em que se encontra, tornando-se terreno fértil para que as políticas neoliberais tirassem partido desse facto e ditassem as regras do jogo nos âmbitos social, cultural e económico. São conhecidos os mecanismos pelos quais a conjutura global se instala em países pouco desenvolvidos como Moçambique. No caso particular do sector da Educa- ção, o estado moçambicano mostrouse incapaz de prosseguir, com coerência, o discurso político a respeito de uma escola moçambicana democrática, inclusiva da maioria, defensora da igualdade e promotora de valores éticos e morais como solidariedade e igualdade de oportunidades, entre outros.

O discurso do sector da educação, expresso nos princípios norteadores e nas directivas do Sistema Nacional de Educação (SNE) que preconizava um ideal de liberdade e autonomia de pensamento e de acções foi, ao longo dos anos, distanciando-se da linguagem que evidenciava uma agregação das diferenças étnicas, culturais e sociais dos moçambicanos. Desse modo, foramse acentuando as já existentes situações de fracasso escolar herdadas do passado recente colonial (dados os seus propósitos de dominação cultural), ao mesmo tempo em que gerou outras formas de exclusão da maioria, pela ausência da compreensão das diferenças sociais e culturais.

As razões de natureza económica que ditaram a adesão às regras da economia de mercado, em que as expressões como competividade, livre concorrência constituem parte do discurso quotidiano na actual conjuntura política e económica, deitaram por terra as pretensões dos projectos educativos que diminuissem as desigualdades sociais.

Entre outros factores, o desprestígio da profissão docente, principal- 
mente nas escolas públicas, devido em parte - aos baixos salários auferidos pelos professores que nelas atuam, comparação com os salários pagos nas escolas privadas emergentes, a assinatura de termos de compromisso objectivando metas quantitativas de aprovação, provocaram um estado de desmotivação generalizada dos professores e alunos. Nesse ambiente, fica evidente a quase impossibilidade de a escola ser reconhecida como um lugar privilegiado de socialização e de construção e consolidação da cidadania. Não se teve em conta a compreensão da dimensão social e cultural inerentes a um projecto pedagógico de humanização e, logo, os currículos transformaram-se em conjuntos de normas e orientações técnicas vindas de cima para baixo, tornando alunos e professores seus meros reprodutores.

Com a pretensão da universalização dos conhecimentos e das culturas locais discutidos e defendidos na época do pós-independência, dispensava-se da educação, da escola a função de realizar os mecanismos de socialização reconhecendo as características comuns e as diferenças inerentes aos indivíduos, porporcionando-lhes formas e métodos adequados de apropriação e de compreensão dos conteúdos e significados das diferentes culturas.

Considerando-se como uma das características da cultura a sua potencialidade reprodutora, Sacristàn (2002, p. 31-33) sugere que ela neces- sita de ser entendida e subjectivada como condição para a sua sustentação por parte dos seres humanos que precisam interpretá-la e compartilhála como uma possibilidade de os indivíduos se transformarem em membros de uma sociedade. Referindo-se à socialização e à aprendizagem como parte dos mecanismos de apropriação da cultura, o autor enfatiza essa necessidade, acreditando que ela deveria ocorrer harmoniosamente, tomando cuidados para que os indivíduos não sejam levados a "desaculturar-se". Isso significa, nas suas palavras, manter a liberdade individual, facilitando a compatibilidade entre o indivíduo e a sociedade, entre a dissidência pessoal e o consenso com os outros (id ibid, p. 32).

Julgo ser esta reflexão importante para ajudar a compreender a génese da atcual situação de desvínculo entre o ensino e a cultura moçambicana, numa breve análise dos mecanismos de exclusão e dominação social e cultural utilizados no passado colonial em Moçambique. Segundo as investigações produzidas relativamente a essa época, o indivíduo moçambicano que se pretendia "culto" deveria negar e desvincular-se da sua própria cultura, adaptando-se apenas à cultura européia, assimilando totalmente essa cultura que lhe impunha hábitos e valores alheios à sua.

A escola colonial, privilegiando uma minoria urbana e da periferia, desenvolve assim estratégias educacionais cujos métodos e conteúdos de 
ensino mantinham e reproduziam a cultura da classe dominante, utilizando como língua de instrução a língua portuguesa, estranha e distante da maioria das populações moçambicanas, principalmente das zonas rurais (DIAS, 2002). Desse modo, estavam lançadas as bases de todo o processo de "civilização" dos indígenas, excluindo, por consequência, as camadas mais desfavorecidas, produzindo uma elite de pessoas alienadas, atraídas pelo estilo de vida da sociedade dominante e descomprometida com o seu mundo real. Esses e outros factores foram, de certa forma, responsáveis pelo índice de analfabetismo constatado em cerca de noventa por cento da população, à data da independência.

Rejeitando as posturas de assimilação impostas como condição para o acesso dos moçambicanos a uma educação que permitisse proporcionar melhores condições de vida aos seus filhos e à ascenção a postos de trabalho reservados à minoria colonial, os sucessivos regimes de governação do pós-independência afirmaram a necessidade de inverter essa situação promovendo políticas educativas que fossem consentâneas com uma sociedade democrática em todos os sentidos.

Porém, passados quase trinta anos de indepedência, a escola moçambicana e o ensino de Química, em particular, continuam sem referências curriculares no âmbito das culturas locais, suscitando os actuais de- bates e as reflexões em torno dos mecanismos de exclusão ainda presentes no nosso ensino.

A escola moçambicana mantém, ainda, um diálogo pedagógico que exclui dos seus projectos curriculares as abordagens sócio-culturais, consideradas legítimas de serem incorporadas no currículo escolar. A relevância do papel da escola no processo de socialização dos indivíduos sugere que se considere essa abordagem não apenas como potencialmente pedagógica, por proporcionar experiências de aprendizagem singulares, mas, sobretudo, porque ela coloca o homem como o sujeito da educação. A ausência de reflexões nesse sentido supõe realizar uma educação do tipo "bancária" (FREIRE, 1987), na qual os conhecimentos são veiculados acriticamente, colocando educadores e educandos numa relação pedagógica vertical e autoritária, do mestre que exerce uma autoridade profunda e rigorosa de controle das acções dos seus alunos. Numa perspectiva tendente a contrariar essa situação, a abordagem sócio-cultural procura proporcionar ao homem a formação de consciência crítica perante o seu lugar no mundo, conscientizando-o da sua condição de sujeito actuante e transformador das realidades.

Nessa perspectiva, considera-se que o homem é um ser que cria e recria formas de realização cultural que o colocam em interacção com o mundo real e objectivo, sendo sua função a de o transformar em seu benefício. 
Essa é uma das condições imprescindíveis para o seu desenvolvimento. Assim, para que uma educação seja válida e tenha um real significado para os seus destinatários, não poderá dissociar-se daquilo que constitui o seu fundamento e lhe dá sustentabilidade.

\section{CONSIDERAÇÕES FINAIS}

A crítica ao actual sistema de educação em Moçambique assenta-se no facto de que os seus princípios orientadores, sob o pretexto da universalidade de saberes vêm reproduzindo uma cultura alheia à realidade cultural moçambicana e fechando-se à compreensão dos conhecimentos quotidianos como outras formas de explicação e entendimento do saber científico, o qual é desdobrado nos conteúdos do conhecimento escolar. Algumas das actuais pesquisas sobre a educação moçambicana têm vindo a estabelecer novos critérios de validade tendentes a romper com modelos de ensino e de pesquisa, de orientação positivista, que encaram a acção educativa como um produto e não como um processo. Na idéia de educação como um processo estão implicados conjuntos de vivências históricas, culturais e sociais que compõem uma determinada cultura, no caso, a cultura escolar, tão diversificada quanto complexa.

O enfoque de uma abordagem sócio-cultural na educação e a tomada de consciência de que esses proces- sos não podem estar desvinculados dos contextos sociais e culturais externos ao sistema escolar, faz compreender a cultura como a âncora que situa o homem no mundo; e a educação, sendo um fenómeno cultural, como o meio que difunde a cultura e a torna acessível pelas práticas escolares.

Forquin (1993) afirmou que a educação não é nada fora da cultura e sem ela. Segundo Sacristán (2002), deve-se reconhecer a cultura como um nutriente que contém os materiais para nos transformarmos em membros de uma sociedade. Sendo a cultura o conteúdo substancial da educação, sua fonte e sua justificação última, de acordo com Forquin (1993, p. 14), ela necessita, por seu lado, de um conjunto de mecanismos capazes de transmitir e reproduzir os seus conteúdos (SACRISTÁN, 2002, p. 211).

A nossa intenção e o nosso compromisso de âmbito pedagógico, que é também político (CHASSOT, 2001), é o de lidar com o conhecimento da Química, entendendo-o como um corpo de conhecimentos construídos pelo homem. Assim sendo a Química, é uma actividade humana e, nesse sentido, tem um percurso com um sentido cultural, social e ético, sofrendo as influências dos diversos contextos onde é produzida. A questão seguinte é de âmbito metodológico.

Como aproveitar e viabilizar, na escola, as contribuições dadas pelo ambiente informal para práticas pedagógicas?

Os esforços no sentido de tornar 
a cultura como um pólo dinâmico nos processos de ensino e aprendizagem trazem no bojo as questões da selectividade curricular nesse campo. $\mathrm{O}$ que aqui se defende como idéia base, é que a escola assuma a valorização dos saberes da comunidade na qual está inserida. Isso significa também problematizar para poder incorporar criticamente esses conhecimentos nas actividades da escola, pois, como afirma Lopes (1993), ao assumirmos tal postura há que se evitar tanto posições extremas de paternalismo, quanto de desvalorização.

A nossa proposta para o ensino de Química implica a necessidade de resgatar e valorizar a Química quotidiana, que está inserida na realidade física e social vivida pelos alunos, e com eles analisar, dialogicamente, os diferentes significados atribuídos e as diferentes formas de construção do conhecimento. Essa proposta deve reflectir e responder às reais expectativas dos grupos sociais concretos a que os alunos pertencem. Reconhecemos nessa proposta o seu valor como substância pedagógica, por achar que a educação em Química pode ser melhor realizada com referência também à cultura moçambicana.

A partir de um novo olhar sobre o que já existe, para construir o que pretendemos com a escola inclusiva, suscitamos a discussão sobre o currículo, compreendido como veículo que estrutura os conhecimentos e a cultura transmitidos pela educação es- colar. Sugerimos que, no planeamento das políticas educacionais, o debate adquira centralidade nas questões sobre como estabelecer as relações entre as diferenças culturais presentes na nossa sociedade. Essa é uma tarefa que temos que encarar com coragem e esperança, para que as sugestões se tornem justas e possam alcançar os objectivos propostos.

\section{REFERENNCIAS}

BONNET, J. A. S. Ethos local e currículo oficial: a educação autóctone tradicional e o ensino básico em Moçambique. Tese (Doutorado em Educação) Pontifícia Universidade Católica de São Paulo, São Paulo, 2002.

CASALI, A. Saberes e procederes escolares: o singular, o plural, o universal. In: FAZENDA, I.; SEVERINO, A. J. (Orgs.). Conhecimento, pesquisa e educação. Campinas: Papirus, 2001.

Pesquisa em educação. In: SEMINÁRIO DE REVISÃO CURRICULAR NA UNIVERSIDADE PEDAGÓGICA, Maputo, 2003.

CHASSOT, A. I. A educação no ensino de química. Ijuí: Unijuí, 1990.

DIAS, H. N. As desigualdades sóciolinguisticas e o fracasso escolar: em direcção a uma prática linguístico-escolar liber-tadora. Maputo: Promédia, 2002.

D'OLNE CAMPOS, M. Relação homem/natureza, manejo e sustentabilidade. Que saberes? São Paulo: USP, (s. d.). (Texto de circulação interna para alunos). 
FORQUIN, J. C. Escola e cultura: as bases epistemológicas do conhecimento escolar. Porto Alegre: Artes Médicas, 1993.

FREIRE, P. Pedagogia do oprimido. 17. ed. Rio de Janeiro: Paz e Terra, 1987.

LOPES, A. R. C. Reflexões sobre currículo: as relações entre senso comum, saber popular e saber escolar. In: XVI REUNIÃO ANUAL DA ANPED, Caxambu, 1993.

OLIVEIRA, R. J. Reflexões sobre a técnica, a ética e a educação no mundo de hoje. In: CHASSOT, A.; OLIVEIRA, R. J. (Orgs.). Ciência, ética e cultura na educação. São Leopoldo: UNISINOS, 1998.

PINTO, H. P. Os saberes das práticas religiosas da comunidade rural negra de Barra do Parateca: uma articulação com a cultura escolar. Dissertação (Mestrado em Educação - Currículo) Pontifícia Universidade Católica de São Paulo, São Paulo, 2000.

SACRISTÁN, J. G. Educar e conviver na cultura global: exigências da cidadania. Porto Alegre: Artmed, 2002.

Encaminhado em 31/05/05

Aceito em 29/06/05 